\title{
Transient FV inhibitor of unknown origin in difficult clinical situation
}

\author{
Odile Pointeau*1, Stéphane Marot ${ }^{2}$, Jaheyo Suhl ${ }^{1}$, Tiphaine Goulenok ${ }^{3}$, François Pousset ${ }^{4}$, Michel Zamy ${ }^{5}$, \\ Jean-Jacques Mourad ${ }^{1}$, Elisabeth Mazoyer ${ }^{6}$, Sylvain Le Jeune ${ }^{1}$ \\ ${ }^{1}$ Avicenne hospital, internal medicine departement, Bobigny, France \\ ${ }^{2}$ Avicenne hospital, haemostasis departement, Bobigny, France \\ ${ }^{3}$ Paris Diderot university, internal medicine department, Paris, France \\ ${ }^{4}$ Pitie Salpetriere-Charles Foix hospital, resuscitation department, Paris, France \\ ${ }^{5}$ Saint Antoine hospital, pharmacology departement, Paris, France \\ ${ }^{6}$ Cochin hospital, haemostasis department, Paris, France
}

Received: October 23, 2017

DOI: $10.5430 /$ crim.v4n $4 \mathrm{p} 59$
Accepted: November 14, 2017 Online Published: November 23, 2017

URL: https://doi.org/10.5430/crim.v4n4p59

\begin{abstract}
Acquired Factor V inhibitors are a rare condition, associated frequently with at times severe bleeding. Patients can show no symptoms and in exceptional cases thrombosis can be reported. In this article we report two cases of acquired FV inhibitors associated with thrombosis. We systematically reviewed the literature on FV inhibitors and thrombosis. A patient had acquired FV inhibitors and thrombosis. He had no bleeding and was treated with anticoagulant. Despite initial improvement, he died from legionaire's disease. The second patient had septicemia, acquired FV inhibitors and deep vein thrombosis. The patient's condition improved with anticoagulation and antibiotic therapy. Ten case reports were considered in the systematic review. The median age at admission was 67. Seven patients had bleeding episodes. The median peak inhibitor titer was 2.7 BU (0.62-8) while the median FV activity was $2 \%$ (1-75). Except for 2 patients, all recovered. FV has two activities: a procoagulant action activating prothrombin, as well as an anticoagulant action activating protein $\mathrm{C}$. This property could be associated with thrombosis activity. Inhibitor could also have a through effect on activated protein C. In our study, because of underlying diseases, it was not possible to clearly demonstrate that inhibitors give thrombosis. Immunosuppressive therapies were administered in cases of severe bleeding. Heparin seemed efficient for thrombosis without major bleeding. The prognosis of acquired FV inhibitors appeared to be related to the underlying disease.
\end{abstract}

Key Words: Blood coagulation factors, Hemostasis, Factor V, Thrombosis, Factor V Deficiency

\section{INTRODUCTION}

Acquired factor $\mathrm{V}$ inhibitor (AFVI) is a rare medical condition with little published literature. ${ }^{[1]}$ Less than one hundred cases have been documented. AFVI is frequently associated with bleeding. ${ }^{[2-4]}$
In rarer cases patients are asymptomatic. In very exceptional cases, episodes of concurrent thrombosis are reported.

There is no clear recommendation on how to deal with thrombotic occurrences associated with AFVI.

In this article we report two cases of patients having devel-

\footnotetext{
*Correspondence: Odile Pointeau; Email: odile.pointeau@aphp.fr; Address: Avicenne hospital, internal medicine departement, 125 route de Stalingrad, 93000 Bobigny, France.
}

Published by Sciedu Press 
oped an AFVI associated with thrombosis and review all the literature published about this association.

\section{Case PResentation}

Patient K, 78 years old, was admitted for heart failure. He had formerly suffered a stroke and had a history of high blood pressure (HBP). He had been treated with bisoprolol, furosemide, and esomeprazole. In 2012 his hemostatic results were normal. The initial echocardiography revealed an intra-auricular thrombus requiring anticoagulant. On his arrival and before fluindione was started, he had a subnormal prothrombine time (PT).

We observed a progressive increase of International Normalized Ratio (INR) culminating at 8.58 on day 20. PT was 44.2 seconds, factor V $2 \%$, factor II $54 \%$ and activated Partial Thromboplastine Time (aPTT) 3.58. There was no change in blood cell counts or hepatic tests and no signs of disseminated intravascular coagulation (DIVC). The patient presented no bleeding. The most probable hypothesis was an AFVI: This was confirmed when using the Bethesda method. The AFVI was at 4 Bethesda units $(\mathrm{BU} / \mathrm{ml})$.

A complete etiological work up revealed negative (absence of use of biological glue, recent surgery, transfusion, infection, inflammatory disease, blood disease, neoplasia or auto immune disease). No recent change in treatment apart from fluindione was reported.

In the absence of bleeding, no immunosuppressive agent was administered. For the treatment of cardiac thrombus, fluindione was switched to low molecular weight heparin (LMWH). The evolution was positive.

On day 30, PT was 14.9 seconds, FV $81 \%$ and AFVI 0.5 $\mathrm{BU} / \mathrm{ml}$. The hemostasis was slowly veering towards normal figures without ever reaching complete remission.

On day 75 , the clinical evolution was marked by the onset of a hematoma at the jugular punction point of a cardiac catheter used for pulmonary hypertension screening. During this bleeding episode, PT was 16.2 seconds and FV $44 \%$ in the presence of AFVI at $1.5 \mathrm{BU} / \mathrm{ml}$. The evolution was simple without specific treatment targeting AFVI and the anticoagulant treatment was resumed. On that day, the intracardiac thrombus was no longer visible on the echography.

On day 129, the patient had no bleeding recurrence. An oral treatment with $2.5 \mathrm{mg}$ apixaban twice a day was started.

On day 154, the patient suffered septic shock because of legionaire's disease. PT and FV plummeted due to hepatic deficiency. There was no thrombosis and no bleeding complications. The level of AFVI was below $0.4 \mathrm{BU} / \mathrm{ml}$.
On day 162 , the patient died from the sequels of this infection.

Patient L, 51 years old, was admitted for a septicemia due to Streptococcus pneumoniae with septic arthritis. His clinical history revealed recurrent deep venous thrombosis requiring long-term anticoagulation, despite a normal thrombophilia screening and a dilated cardiomyopathy. His usual treatment consisted in fluindione, rosuvastatin, ramipril and spironolactone. He was treated for this infection by systemic antibiotics (amoxicillin and clavulanic acid and gentamycin) and surgical washing of the joint. On admission under anti-vitamin $\mathrm{K}$ (fluindione), his PT was 16.1 seconds, FV $138 \%$.

On day 7 after the start of the antibiotic treatment, PT and FV decreased whereas no hepatic anomaly and no DIVC were detected.

On day 9, his leg became painful and a venous Doppler ultrasound showed recent distal deep vein thrombosis. A curative anticoagulant treatment with LMWH was then started along with anti-vitamin $\mathrm{K}$.

On day 13 , the aPTT was 4.13 , PT was 38.2 seconds and $\mathrm{FV}$ was $4 \%$. The dosage of AFVI was $8 \mathrm{BU} / \mathrm{ml}$. There was no bleeding and our search for a causative factor other that antibiotic therapy was negative. No other specific treatment was deemed necessary but anti-vitamin K was stopped.

On day 16, we stopped amoxicillin and started clindamycin and levofloxacin.

On day 26, the hemostasis results improved with FV getting towards normal at $70 \%$ and AFVI becoming undetectable.

The patient was getting better. Anti-vitamin $\mathrm{K}$ was resumed at discharge from the hospital. A few months later, our patient had no thrombotic or bleeding episodes. FV levels remained normal.

\section{Discussion}

Including the two cases reported here, we gathered information on 10 patients ( 8 published) having suffered a thrombotic episode associated with the presence of AFVI.

Deep vein thrombosis was located in the lower limbs in 7 patients. We also reviewed an episode of cardiac thrombus, a case of gangrene and a case of stroke.

Half of the patients showed concurrently AFVI and thrombotic episodes.

Two patients had suffered from a thrombotic episode prior to the presence of the AFVI.

Three patients developed a thrombosis a few weeks after diagnosis of AFVI. At the onset of the thrombotic episode, the 
TQ had been known for 8 patients with a mean value of 18.5 seconds. Factor $\mathrm{V}$ activity was known for 5 patients (median value $2 \%, 1-75$ ) and AFVI levels for 4 patients (median value 2.7 BU/ml, 0.62-8).

Five patients with deep vein thrombosis were treated with an anticoagulant (heparin was added to anti-vitamin K). Intra cardiac thrombus received heparin then a direct oral anticoagulant.

Among the patients without anticoagulant treatment, one had aspirin and the remaining three did not receive any antithrombotic treatment.

Four patients had bleeding on admission and received a specific treatment targeting the AFVI: All 4 patients were treated with systemic corticoids. One patient was treated with intravenous immunoglobulin and cyclophosphamid while another one received plasma exchanges and azathioprin.

Two patients showed non severe bleeding under anticoagulant. One patient who had not been treated with anticoagulant showed a minor bleeding episode following surgery.

The procoagulant action of $\mathrm{FV}$ is due to its role in activating prothrombin when associated with activated factor $\mathrm{X}$. The inactivation of $\mathrm{FV}$ is mainly driven by the action of protein $\mathrm{C}$ and protein $\mathrm{S}{ }^{[4]}$ But factor $\mathrm{V}$ shows also an anticoagulant activity: This activity is due to its synergy with activated protein $\mathrm{C}$ enabling the suppression of activated factor VIII. ${ }^{[4]}$

The possibility of an acquired deficit in factor $\mathrm{V}$ must be raised in case of lowered TP and extended aPTT connected to a decrease of FV activity in the absence of other putative causes. The calculation of the inhibitor's titer may be done by adding control plasma to the patient's plasma. One BU is the quantity of inhibitor that can neutralize $50 \%$ of the factor. ${ }^{[4]}$

In our sample, the mean FV activity was $3.5 \%$ as opposed to $1 \%$ in the literature. ${ }^{[3]}$ Ang et al. ${ }^{[2]}$ reported in their work an association between severe bleeding and the FV rate. In our series, the mean inhibitor rate was $4 \mathrm{BU}$ (as opposed to 19 BU in the work of Franchini et al. ${ }^{[3]}$ Due to the small scale of our sample, it was not possible to point a link between biological values and the risk of bleeding in our study.

The etiological factors of AFVI can be set in 5 categories: Use of biological glue, surgery, transfusion, other causes (cancer, infections...) or idiopathic (bearing a bad outcome).

In our review, the factors inducing the onset of the inhibitor seemed rather clear. We found 3 cases of infection, 3 cases of cancer, 2 cases of lymphoma, 3 cases of surgery and 2 cases of autoimmune diseases. In 2 cases no obvious associated factor could be found. Our results bore close similitudes to those reported in the two main reviews previously published. ${ }^{[2,3]}$

For 3 patients, the AFVI appeared after the prescription of anti-vitamin K. A few case reports also described the onset of AFVI after treatment with anti-vitamin $\mathrm{K}$, raising the question of its immutability. ${ }^{[5,6]}$ Anti-vitamin K should thus be used with caution in the context of AFVI.

The potentially thrombogenic role of these auto-antibodies was recently pointed in the case of a patient with repetitive thrombotic episodes. ${ }^{[7]}$ This patient showed a resistance to activated protein $\mathrm{C}$, without mutation of Leiden FV but with the presence of an AFVI. The possible action of the antibody on activated protein $\mathrm{C}$ was pointed. The other possibility was an inhibition of the anticoagulant action of FV through a direct effect of the antibody on this factor. The last possibility was that AFVI may show lupus-like anti-phospholipid properties. ${ }^{[8]}$ Due to the elevated venous thrombotic risk of the patients considered in our article, it was impossible to establish a clear and definitive link between the AFVI and the onset of thrombotic episodes.

Specific treatments targeting AFVI were administrated to 4 patients. All these patients recovered with the disappearance of AFVI. A faster clearance of the antibody was obtained in patients with bleeding when treated with a specific therapy ${ }^{[2,3]}$ but this treatment did not influence biological or clinical evolution for asymptomatic patients. No current literature can put forward the safest and most efficient therapeutic strategy in that context.

One patient received aspirin for the treatment of arterial thrombosis (stroke) ${ }^{[9]}$ Three other patients presented serious bleeding and received a specific treatment without anticoagulant. ${ }^{[10-12]}$ All of these 4 patients evolved favorably. The remaining six patients were treated with heparin (LMWH or unfractionated heparin) during the initial phase followed by anti-vitamin $\mathrm{K}$ or oral anticoagulants. ${ }^{[6,13-15]}$ The treatment with heparin helped towards a favorable evolution of thrombosis.

Two patients showed a bleeding complication with heparin (secondary to an invasive procedure) but no transfusion was needed. The other patients did not show any bleeding under anticoagulant treatment. The use of heparin with a close biological monitoring in the acute phase of thrombosis appeared in this series as a safe strategy in the context of AFVI.

In our review, 2 patients died but their deaths were not caused by a thrombotic or bleeding accident (in both cases death was caused by a septic shock). ${ }^{[6]}$ There was evident clinical and biological improved state of health for all remaining patients. 
In the literature, as well as in your study, prognosis was clearly more linked to the underlying disease than to the consequences of AFVI.

\section{Conclusion}

This review confirms the rare occurrence of AFVI associated with thrombotic episodes. The clinical picture is manyfaceted but often associated with bleeding. The etiological role of AFVI in the onset of thrombosis is often hard to demonstrate. The treatment of thrombosis is not consensual and is mainly based on the introduction of an anticoagulant (heparin in the initial phase) with a relatively good tolerance in our series. Bleeding can sometimes require the use of specific treatments. The prognosis is clearly linked with underlying pathologies.

\section{ACKNOWLEDGEMENTS}

Thanks to Mr Alain Gardrat for the translation.

\section{CONFlicts of InTERest Disclosure}

The authors have declared no conflicts of interest.

\section{REFERENCES}

[1] Horder MH. Isolierter Factor V-Mangel bedingt durch einen spezifischen Hemmkörper. Acta Haematol. 1955 Apr; 13(4): 235-41. PMid:14375712 https ://doi .org/10.1159/000204943

[2] Ang AL, Kuperan P, Ng CH, et al. Acquired factor V inhibitor. A problem-based systematic review. Thromb Haemost. 2009; 101 (5): 852. https://doi.org/10.1160/TH08-11-0767

[3] Franchini M, Lippi G. Acquired factor V inhibitors: a systematic review. J Thromb Thrombolysis. 2011; 31(4): 449-57. PMid:21052780 https://doi.org/10.1007/s11239-010-0529-6

[4] Matsumoto T, Nogami K, Shima M. Coagulation function and mechanisms in various clinical phenotypes of patients with acquired factor V inhibitors. J Thromb Haemost. 2014; 12(9): 1503-12. PMid:25041532 https://doi .org/10.1111/jth. 12660

[5] Gartrell B. Acquired factor V inhibitor complicating warfarin therapy. Am J Hematol. 2011; 86(8): 710-2. PMid:21761437 https: //doi.org/10.1002/ajh.22073

[6] Kamphuisen PW, Haan J, Rosekrans PC, et al. Deep-vein thrombosis and coumarin skin necrosis associated with a factor $\mathrm{V}$ inhibitor with lupus-like features. Am J Hematol. févr. 1998; 57(2): 176-8. https://doi.org/10.1002/(SICI) 1096-865 2(199802) $57: 2<176:$ : AID-AJH14>3. 0.CO;2-A

[7] Kalafatis M, Simioni P, Tormene D, et al. Isolation and characterization of an antifactor $\mathrm{V}$ antibody causing activated protein $\mathrm{C}$ resistance from a patient with severe thrombotic manifestations. Blood. 2002; 99(11): 3985-92. PMid:12010798 https://doi.org/10.1182/ blood.V99.11.3985

[8] Ortel TL, Quinn-Allen MA, Charles LA, et al. Characterization of an acquired inhibitor to coagulation factor V. Antibody binding to the second $\mathrm{C}$-type domain of factor $\mathrm{V}$ inhibits the bind- ing of factor $\mathrm{V}$ to phosphatidylserine and neutralizes procoagulant activity. J Clin Invest. 1992; 90(6): 2340-7. PMid:1281831 https://doi.org/10.1172/JCI116123

[9] Koyama T, Saito T, Kusano T, et al. Factor V inhibitor associated with Sjögren's syndrome. Br J Haematol. 1995; 89(4): 893-6. PMid:7772528 https://doi.org/10.1111/j.1365-214 1.1995.tb08430.x

[10] Ortel TL, Charles LA, Keller FG, et al. Topical thrombin and acquired coagulation factor inhibitors: clinical spectrum and laboratory diagnosis. Am J Hematol. 1994; 45(2): 128-35. PMid:8141118 https://doi.org/10.1002/ajh. 2830450206

[11] Higuchi T, Okamoto T, Kou T, et al. Deep vein thrombosis associated with factor $\mathrm{V}$ inhibitor followed by immune thrombocytopenia. Ann Hematol. 2012; 91(11): 1831-2. PMid:22588327 https://doi.org/10.1007/s00277-012-1485-3

[12] Kapur A, Kelsey PR, Isaacs PE. Factor V inhibitor in thrombosis. Am J Hematol. 1993; 42(4): 384-8. PMid:8493990 https: //doi.org/10.1002/ajh.2830420410

[13] Donohoe K, Levine R. Acquired factor V inhibitor after exposure to topical human thrombin related to an otorhinolaryngological procedure. J Thromb Haemost. 2015; 13(10): 1787-9. PMid:26270511 https://doi.org/10.1111/jth.13114

[14] AlJohani NI, Matthews JH. Acquired factor V inhibitor in a patient with mantle cell lymphoma presenting with hematuria followed by thrombosis: a case report. Int Med Case Rep J. 2014; 7: 27-30. PMid:24591851 https://doi .org/10.2147/IMCRJ . S59236

[15] Sushil G. Coagulopathy Due to an Acquired factor V Inhibitor and Subsequently Thrombosis. American Journal of Hematology. 1995; 49 (1): 98-100. https://doi.org/10.1002/ajh. 2830490122 